\title{
Enhanced stable production of ethylene in photosynthetic cyanobacterium Synechococcus elongatus PCC 7942
}

\author{
Veronica Carbonell $^{1} \cdot$ Eerika Vuorio $^{1} \cdot$ Eva-Mari Aro $^{1} \cdot$ Pauli Kallio $^{1}$ D
}

Received: 26 November 2018 / Accepted: 26 April 2019 / Published online: 8 May 2019

(c) The Author(s) 2019

\begin{abstract}
Ethylene is a volatile alkene which is used in large commercial scale as a precursor in plastic industry, and is currently derived from petroleum refinement. As an alternative production strategy, photoautotrophic cyanobacteria Synechocystis sp. PCC 6803 and Synechococcus elongatus PCC 7942 have been previously evaluated as potential biotechnological hosts for producing ethylene directly from $\mathrm{CO}_{2}$, by the over-expression of ethylene forming enzyme (efe) from Pseudomonas syringae. This work addresses various open questions related to the use of Synechococcus as the engineering target, and demonstrates long-term ethylene production at rates reaching $140 \mu \mathrm{L} \mathrm{L}^{-1} \mathrm{~h}^{-1} \mathrm{OD}_{750}{ }^{-1}$ without loss of host vitality or capacity to produce ethylene. The results imply that the genetic instability observed earlier may be associated with the expression strategies, rather than efe over-expression, ethylene toxicity or the depletion of 2-oxoglutarate-derived cellular precursors in Synechococcus. In context with literature, this study underlines the critical differences in expression system design in the alternative hosts, and confirms Synechococcus as a suitable parallel host for further engineering.
\end{abstract}

Keywords Ethylene $\cdot$ Cyanobacteria $\cdot$ Synechococcus elongatus PCC $7942 \cdot$ Genetic stability $\cdot$ Photoautotrophic production $\cdot$ Biotechnological application

\section{Introduction}

Ethylene $\left(\mathrm{C}_{2} \mathrm{H}_{4}\right)$ is a simple alkene which is widely used in chemical industry as a precursor for polymer synthesis and in food industry to induce fruit ripening. In addition, ethylene is a potential fuel with high energy density and other physicochemical properties suitable, for example, to combustion engines (Zulkarnain Abdul Latiff et al. 2008). The global ethylene demand is higher than 150 million tonnes per year (Petrochemical 2015) and it is primarily derived from non-renewable sources as a product in petroleum refining. The production of one ton of ethylene in the commonly used

Veronica Carbonell and Eerika Vuorio contributed equally to this work.

Electronic supplementary material The online version of this article (https://doi.org/10.1007/s11274-019-2652-7) contains supplementary material, which is available to authorized users.

Pauli Kallio

pataka@utu.fi

1 Molecular Plant Biology, Department of Biochemistry, University of Turku, 20014 Turun yliopisto, Finland steam cracking process releases 1,5-3 tons of carbon dioxide in the atmosphere, which makes this one of the largest single $\mathrm{CO}_{2}$ emitting processes in chemical industry (Ungerer et al. 2012) and thus a significant global environmental burden.

In nature, ethylene has several distinct biological functions. In plants, it acts as a hormone associated with fruit ripening and abscission of leaves, and is produced from 1-aminocycloprone-1-carboxylate (ACC) by the enzyme ACC oxidase (Dong et al. 1992). Micro-organisms use ethylene, for example, in non-specific defence signalling (Gottwald et al. 2012) and as a mediator in virulence (Weingart et al. 2001), and it is produced via at least two different pathways: Ethylene biosynthesis may proceed through 2-keto4-methylthiobutyric acid by the action of NADH:Fe(III) EDTA oxidoreductase as in Cryptococcus albidus (Fukuda et al. 1989; Ogawa et al. 1990), or it can be generated from 2-oxoglutarate and L-arginine by ethylene forming enzyme (efe) as in various Pseudomonas species (Fukuda et al. 1986; Nagahama et al. 1991).

There is an increasing global need to develop and evaluate new solutions for the production of sustainable substitutes for petroleum-derived products such as ethylene. One of the potential biotechnological approaches is to use 
photosynthetic microbial cells, cyanobacteria, as engineered biological factories to produce different end-products of interest. This would allow the direct utilization of atmospheric $\mathrm{CO}_{2}$ and water as substrates for the biosynthesis of the target metabolites using sunlight as the sole source of energy, thus bypassing the use of biomass as starting material. In this respect, cyanobacteria have been extensively studied as engineering targets, and a range of molecular biology tools and production strategies have been developed and characterized [See reviews (Hagemann and Hess 2018; Sun et al. 2018)]. Besides ethylene, cyanobacteria have been engineered to produce various products, including alcohols, organic acids, and carbohydrates [see reviews (Oliver et al. 2016; Zhou et al. 2016)], but the overall efficiencies are still below the threshold required for any commercial applications, and require further systematic research.

Autotrophic production of ethylene has been studied primarily in two cyanobacterial strains Synechocystis sp PCC 6803 (Guerrero et al. 2012; Ungerer et al. 2012; Eckert et al. 2014; Zhu et al. 2015; Lee et al. 2015; Xiong et al. 2015; Zavřel et al. 2016; Carbonell et al. 2016) and Synechococcus elongatus PCC 7942 (Fukuda et al. 1994; Sakai et al. 1997; Wang et al. 1999, 2000; Matsuoka et al. 2001; Takahama et al. 2003) (from here on referred to as Synechocystis and Synechococcus, respectively). The general strategy has been to over-express the heterologous ethylene forming enzyme from Pseudomonas syringae to convert endogenous metabolic precursors 2-oxoglutarate and L-arginine to ethylene, which then as a volatile gas spontaneously diffuses out from the cell and separates into the culture headspace.

In comparison to Synechocystis, only relatively low productivities have been achieved in stable Synechococcus strains (Supplementary Table S1), and the most efficient expression systems have been associated with instability and eventual loss of ethylene production in a few generations (Sakai et al. 1997; Takahama et al. 2003). The reported instability has been accompanied by apparent metabolic stress on the Synechococcus host, observed as decreased growth rates and chlorophyll breakdown resulting in a yellowish-green phenotype (Sakai et al. 1997; Takahama et al. 2003). At genetic level, the inactivation has been associated with insertion mutations taking place at specific repeated sequence elements (CGATG) which cause frameshifts in the efe gene (Takahama et al. 2003).

The aim of this study was to clarify different factors previously associated with the instability of the ethylene production systems in Synechococcus. Specifically, the intention was to (1) elucidate the role of the efe primary sequence in context with the chromosomal integration site, and (2) analyse possible stress effects caused by efe over-expression and ethylene levels, in order to obtain a more comprehensive view of the potential limiting factors in further developing Synechococcus as a platform for ethylene biosynthesis.

\section{Materials and methods}

\section{Cell strains and default culture conditions}

Escherichia coli strain DH5 $\alpha$ was used for the molecular cloning steps and plasmid propagation. The cells were cultured in Luria-Bertani medium supplemented with $25 \mu \mathrm{g} \mathrm{mL}^{-1}$ of spectinomycin and $10 \mu \mathrm{g} \mathrm{mL}^{-1}$ of streptomycin $\left(37^{\circ} \mathrm{C}, 120 \mathrm{rpm}\right.$ shaking). Synechococcus elongatus PCC 7942 was used as the efe over-expression host for ethylene production. The cells were cultivated in BG11 liquid medium (20 mM TES-KOH, pH 8) supplemented with $25 \mu \mathrm{g} \mathrm{mL}^{-1}$ of spectinomycin, $10 \mu \mathrm{g} \mathrm{mL} \mathrm{L}^{-1}$ of streptomycin and 1 mM IPTG (Geerts et al. 1995; Berla et al. 2013) when appropriate. The cultures were carried out in $100 \mathrm{~mL}$ volume (250 mL Erlenmeyer flasks) under continuous light $(50 \mu \mathrm{mol}$ photons $\mathrm{m}^{-2} \mathrm{~s}^{-1}$ ) at $30{ }^{\circ} \mathrm{C}$ in $1 \% \mathrm{CO}_{2}$ in an orbital shaker $(120 \mathrm{rpm})$ in a Sanyo Chamber (SanyoElectric Co. Ltd).

\section{Assembly of the efe over-expression constructs and transformation into Synechococcus}

The commercial plasmid pUC19 (Yanisch-Perron et al. 1985) was used as the backbone to assemble a chromosomal integration vector for the introduction of efe in Synechococcus (Table 1). A 1094 bp fragment allowing targeted homologous recombination into the host genome at the NSI site (GenBank: U30252.3) (Mackey et al. 2007) was PCR amplified (Table 2, primers 1 and 2) and subcloned (AatIIBamHI) into pUC19 to create p19_7942_NSI (Table 1). Subsequently, two efe gene variants, o-efe (GenBank: D13182.1) and sy-efeh (GenBank: KX184731), were PCR amplified (Table 2, primers 3 and 4) from pDF-trc-o-EFE (Carbonell et al. 2016) and pDF-trc-EFEh (Guerrero et al. 2012), respectively, to create fragments carrying a spectinomycin/streptomycin resistance cassette $\left(\mathrm{Sp}^{\mathrm{r}} / \mathrm{Str}^{\mathrm{r}}\right)$, lac repressor $\left(\operatorname{Lacl}^{q}\right)$, $\operatorname{trc}$ promoter $\left(\mathrm{P}_{t r c}\right)$ and the two $\operatorname{rrnB}$ terminators. The fragments were inserted into p19_7942_NSI (Eagl) creating the final integration constructs pChr_7942_NSI_o-efe Sp and pChr_7942_NSI_sy-efeh_Sp (Table 1), which were then confirmed by sequencing (Table 2, primers 5-8). The plasmids were transformed into Synechococcus via natural transformation and the resulting recombinant strains were called Synechococcus:o-efe and Synechococcus:sy-efeh respectively. Full segregation of the mutants at the NSI locus was verified by PCR (Fig. 1).

\section{Quantitative analysis of ethylene production}

Ethylene production of the strains was monitored in a stepwise experiment of four repeated consecutive $100 \mathrm{~mL}$ 
Table 1 Plasmids used in the study

\begin{tabular}{|c|c|c|}
\hline Plasmids & Description & References \\
\hline pUC19 & $\mathrm{Ap}^{\mathrm{r}}$, ori (ColE1) & (Yanisch-Perron et al. 1985) \\
\hline p19_7942_NSI & pUC19 derivative containing $1,1 \mathrm{~kb}$ fragment of NSI from Synechococcus & This study \\
\hline pDF-trc-EFEh & $\begin{array}{l}\text { sy-efeh gene, } r r n B \text { terminator regions and } \mathrm{Sp}^{\mathrm{r}} / \mathrm{Str}^{\mathrm{r}} \text { cassette for insertion into } \\
\text { p19_7942_NSI }\end{array}$ & (Guerrero et al. 2012) \\
\hline pDF-trc-o-EFE & $\begin{array}{l}\text { o-efe gene, } r r n B \text { terminator regions and } \mathrm{Sp} / \mathrm{Str} \text { cassette for insertion into } \\
\text { p19_7942_NSI }\end{array}$ & (Carbonell et al. 2016) \\
\hline pChr_7942_NSI_o-efe_Sp & $\begin{array}{l}\text { Derivative p19_7942_NSI containing o-efe gene, } \operatorname{rrnB} \text { terminator regions and } \mathrm{Sp}^{\mathrm{r}} / \\
\text { Str }^{\mathrm{r}} \text { cassette flanked by NSI }\end{array}$ & This study \\
\hline pChr_7942_NSI_sy-efeh_Sp & $\begin{array}{l}\text { Derivative p19_7942_NSI containing sy-efeh gene, } r r n B \text { terminator regions and } \\
\mathrm{Sp}^{\mathrm{r}} / \mathrm{Str}^{\mathrm{r}} \text { cassette flanked by } N S I\end{array}$ & This study \\
\hline
\end{tabular}

Table 2 PCR Primers $\left(5^{\prime} \rightarrow 3^{\prime}\right.$ direction) used in this study

\begin{tabular}{|c|c|c|}
\hline ID & Primers & Sequence and description \\
\hline 1 & fw_SEA0027 & $\begin{array}{l}\text { attagacgtcTAGTCGCCGCAGTAGTGATG } \\
\text { Cloning NSI from Synechococcus genome (AatII overhang) }\end{array}$ \\
\hline 2 & rv_SEA0027 & $\begin{array}{l}\text { aatggatccACCCGGTAGGGATTTCG } \\
\text { Cloning NSI from Synechococcus genome (BamHI overhang) }\end{array}$ \\
\hline 3 & fw_pDF_s_iq_e_t2 & $\begin{array}{l}\text { CTGGCTTTGCTTCCAGATGT } \\
\text { Cloning of pDF cassette containing } \mathrm{Sp}^{\mathrm{r}} / \mathrm{Str}^{\mathrm{r}}, L_{a c}{ }^{q}, \mathrm{P}_{t r c} \text {, efe variants and two } \mathrm{rrnB} \text { terminators }\end{array}$ \\
\hline 4 & rv_pDF_s_iq_e_t2_EagI & $\begin{array}{l}\text { taaacggecgCTTTCAGCTAGCGTACCA } \\
\text { Cloning of pDF cassette containing } \mathrm{Sp}^{\mathrm{r}} / \mathrm{Str}^{\mathrm{r}}, \operatorname{Lacl}^{q}, \mathrm{P}_{t r c}, \text { efe variants and two } \mathrm{rrnB} \text { terminators } \\
\text { (Eagl overhang) }\end{array}$ \\
\hline 5 & fw_seq_NSI_7942 & $\begin{array}{l}\text { TAGTCGCCGCAGTAGTGATG } \\
\text { Sequencing and colony PCR }\end{array}$ \\
\hline 6 & rv_seq_NSI_7942 & $\begin{array}{l}\text { CTCCAGCAAGCTAGCGATTT } \\
\text { Sequencing and colony PCR }\end{array}$ \\
\hline 7 & 75_pUC_Rev & $\begin{array}{l}\text { GCTCACTCATTAGGCACCCCAGG } \\
\text { Sequencing and colony PCR }\end{array}$ \\
\hline 8 & rv_seq_NSI_ins & $\begin{array}{l}\text { AGGGCCGTGATCTTGTCAT } \\
\text { Sequencing and colony PCR }\end{array}$ \\
\hline
\end{tabular}

Complementary regions are shown in capital letters and restriction sites are underlined

cultivation batches, with four biological replicates each. Every cultivation batch was started at $\mathrm{OD}_{750} \sim 0.1$ and grown until the optical density reached $\sim 1$ (after about 4 days), followed by analysis of ethylene production and inoculation of the successive batch. Ethylene quantitation was carried out by transferring $1 \mathrm{~mL}$ of the cell cultures supplemented with $1 \mathrm{mM}$ IPTG into $10 \mathrm{~mL}$ sealed vials, followed by $2-8 \mathrm{~h}$ incubation under specified conditions $(50 \mu \mathrm{mol}$ photons $\mathrm{m}^{-2} \mathrm{~s}^{-1}, 30^{\circ} \mathrm{C}, 120 \mathrm{rpm}$ ), and analysis of the headspace gas phase (25-250 $\mu \mathrm{L}$ samples) by GC-MS as described earlier (Guerrero et al. 2012; Carbonell et al. 2016). The integrated MS peak areas were used to calculate the relative ethylene production as $\mu \mathrm{L}$ of ethylene per litre of culture per hour $(\mu \mathrm{L}$ $\mathrm{L}^{-1} \mathrm{~h}^{-1}$ ), and normalized to cell density to allow comparison. The statistical significance of the observed differences was evaluated based on the calculated average values, using pairwise $t$-test analysis at significance level $p \leq 0.05$.

\section{Evaluation of expression system stability in long-term cultivations}

Long-term stability of the Synechococcus ethylene production strains was evaluated in a 16-week step-wise batch cultivation trial, carried out in $40 \mathrm{~mL}$ culture volume in $100 \mathrm{~mL}$ Erlenmeyer flasks in four parallel replicates. The cultures were diluted in fresh BG11 (containing antibiotics) to $\mathrm{OD}_{750}$ 0.05 at 1 week intervals, and analysed for ethylene productivity after 7 days incubation.

\section{Effect of supplemented ethylene on cell growth}

The effect of high concentrations of ethylene on WT Synechococcus was evaluated by supplying $99 \%(\mathrm{v} / \mathrm{v})$ gaseous ethylene (AGA, Espoo, Finland) into $20 \mathrm{~mL}$ cell cultures containing $50 \mathrm{mM}$ bicarbonate in gas-tight serum bottles $(160 \mathrm{~mL})$. Ethylene was supplied directly into the culture 


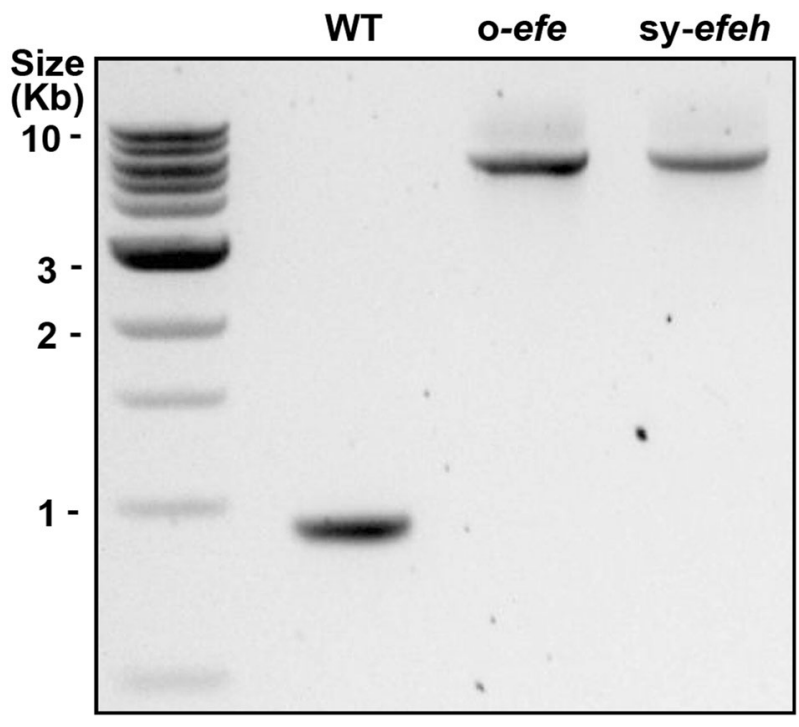

Fig. 1 Colony PCR (1\% agarose gel) confirming chromosomal integration and segregation of the efe expression cassettes at the NSIlocus of Synechococcus elongatus PCC 7942. Wild type control (WT; expected fragment size $=906 \mathrm{bp}$ ), Synechococcus carrying efe from $P$. Syringae (o-efe; expected fragment size $=5446 \mathrm{bp}$ ), and Synechococcus carrying sequence optimized efe (sy-efeh; expected fragment size $=5446 \mathrm{bp}$ ). The NSI-specific primers used for the colony PCR are listed in Table 2

media by bubbling for $2 \min (\approx 0.5$ bars) with an injection needle through the butyl rubber cap of the sealed bottles (equipped with an additional outlet needle to prevent the build-up of overpressure). Air and nitrogen gas were used as parallel controls. Growth of the cells was followed by monitoring culture $\mathrm{OD}_{750}$ for the subsequent 7 days.

\section{Substrate supplementation}

The quantitative effect of substrate supplementation on ethylene production was evaluated by the addition of $5 \mathrm{mM}$ L-arginine (Sigma-Aldrich) or/and $1 \mathrm{mM}$ 2-oxoglutarate (Sigma-Aldrich) into the sealed $10 \mathrm{ml}$ reaction vials at the same time with IPTG. The analysis was carried out in four biological replicates, and the ethylene productivity was compared against corresponding reactions without supplemented substrates.

\section{Spectral analysis of the cultures}

Absorption spectra of the Synechococcus cultures $(400-750 \mathrm{~nm})$ were recorded with Infinite 200 Pro plate reader (Tecan Ltd, Switzerland). The spectra were obtained from $150 \mu \mathrm{L}$ of cell cultures normalized to the same $\mathrm{OD}_{750}$ on 96 well plates (Greiner 96 Flat Bottom Transparent Polystyrol).

\section{Results}

\section{Construction of Synechococcus strains for ethylene production}

In order to evaluate the production of ethylene in Synechococcus, two chromosomal integration constructs were assembled for the over-expression of the heterologous ethylene forming enzyme under the control of a constitutive promoter $P_{t r c}$ (Huang et al. 2010; Guerrero et al. 2012). Two alternative forms of the efe gene used in the constructs were (i) the native efe from $P$. Syringae (o-efe) used in several earlier studies in Synechococcus (Fukuda et al. 1994; Sakai et al. 1997; Takahama et al. 2003) and (ii) a sequence-optimized form (sy-efeh) previously expressed in Synechocystis, from which the repetitive sequences CGATG associated with insertion mutations had been removed (Ungerer et al. 2012; Guerrero et al. 2012; Carbonell et al. 2016). The chromosomal locus NSI was selected as the target site for homologous recombination, as it had previously successfully used for protein over-expression in Synechococcus (Ditty et al. 2005; Mackey et al. 2007). The sequenced constructs were transformed into Synechococcus, followed by selection based on acquired antibiotic resistance. Colony PCR was used to confirm integration at the NSI site and full segregation of the generated mutants (Fig. 1), and in each case, only fragments corresponding to the expected size (5446 bp) were observed while the WT fragment was not detected (906 bp).

\section{The two generated Synechococcus strains produce ethylene at similar levels}

Cultivation of both of the generated Synechococcus efe overexpression strains resulted in the accumulation of ethylene in the headspace of the closed culture vials as detected by GC-MS. The production efficiency of the two strains was very similar, and no obvious difference could be observed between the function of the o-efe or the sy-efeh under the conditions tested (Fig. 2a). In both cases the ethylene productivity remained stable throughout the four consecutive 4-day batch cultures, with highest recorded yields of around $140 \mu \mathrm{L} \mathrm{L}^{-1} \mathrm{~h}^{-1} \mathrm{OD}_{750}{ }^{-1}$, averaging to about $100 \mu \mathrm{L} \mathrm{L}^{-1} \mathrm{~h}^{-1}$ $\mathrm{OD}_{750}^{-1}$ (Fig. 2b).

\section{Expression of efe or direct ethylene supplementation do not induce adverse effects to the cells}

With the objective to evaluate possible adverse effects caused by ethylene production to the host, the two efeexpressing strains were compared against the wild type 


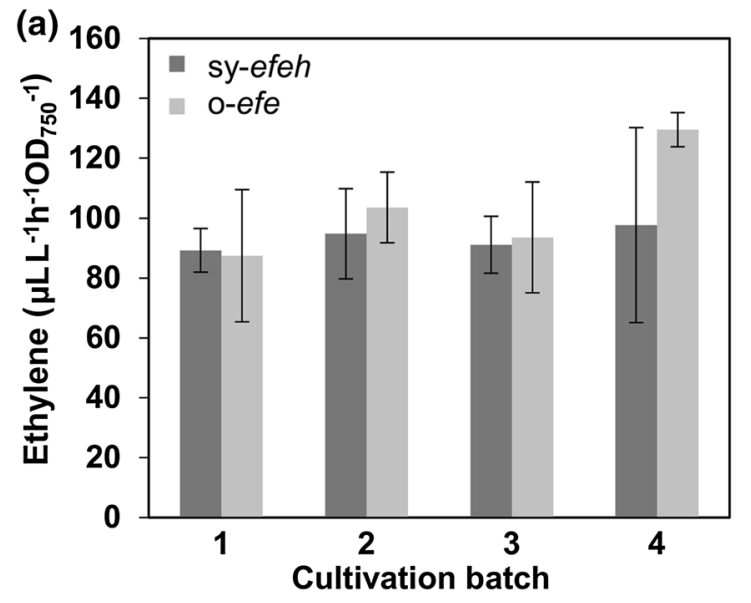

Fig. 2 Ethylene production by Synechococcus elongatus PCC 7942 over-expressing sy-efeh and o-efe in four successive 4-day batch cultures. a Production rate averages of the four batches normalized to $\mathrm{OD}_{750}(\mathrm{n}=4$; error bars represent $\mathrm{SD})$. b Average ethylene production

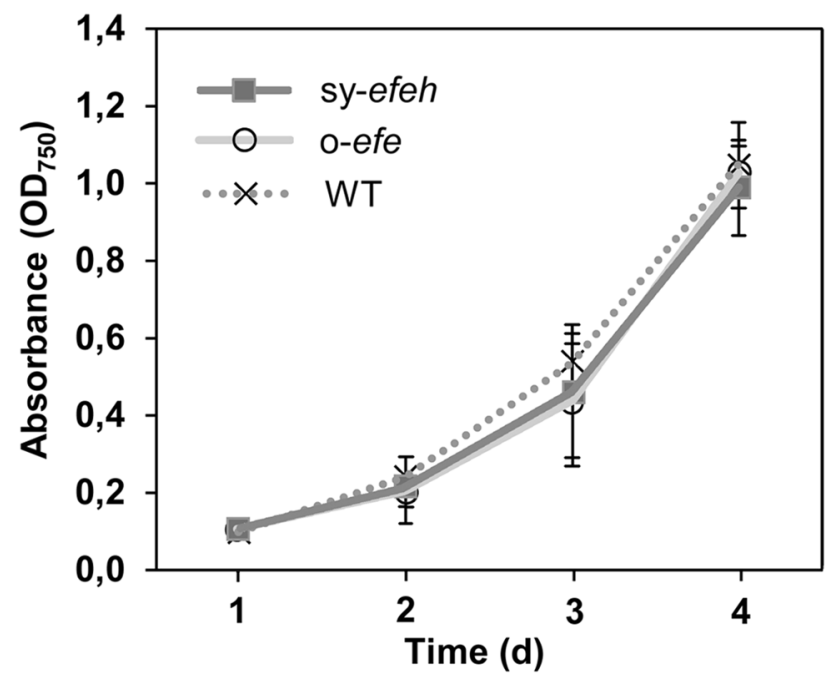

Fig. 3 Growth $\left(\mathrm{OD}_{750}\right)$ of Synechococcus elongatus PCC 7942 wild type (dotted line), Synechococcus:o-efe (solid light grey line) and Synechococcus:sy-efeh (solid dark grey line) in the successive 4-day batch cultures ( $n=3$, error bars represent SD). Statistically significant differences were not observed between the growth of the alternative strains $(t$ test)

Synechococcus strain. The results showed that constitutive ethylene production at the recorded levels did not have any clear negative impact on the growth of the host; The growth rates of all the strains were comparable (Fig. 3), and the phenotype based on culture colour and absorption properties measured spectrophotometrically (Fig. 4) were similar. Furthermore, the presence of high concentrations of supplied ethylene (up to $>99 \%$ of the headspace gas) in sealed 7-day batch cultures did not affect the viability of the cells, indicating that ethylene itself does not inflict any acute toxicity

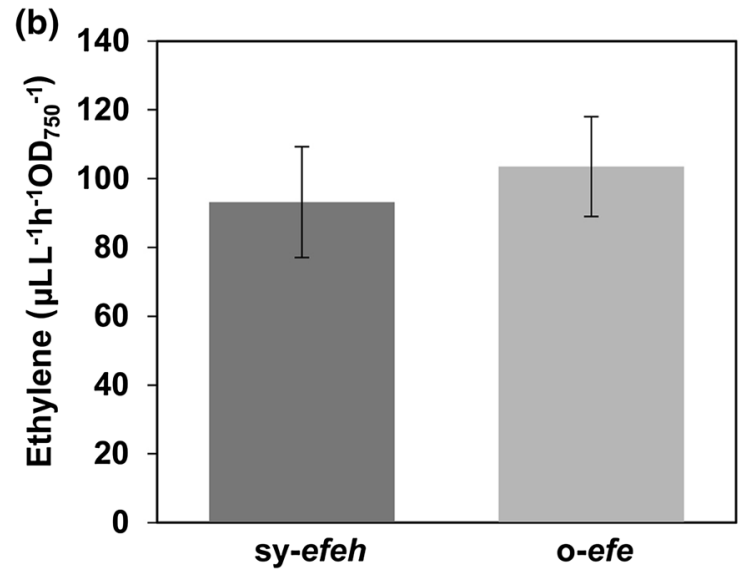

throughout the entire experiment $(n=16$; error bars represent SD). Statistically significant differences were not observed between the cultivation batches or the alternative strains $(t$ test)

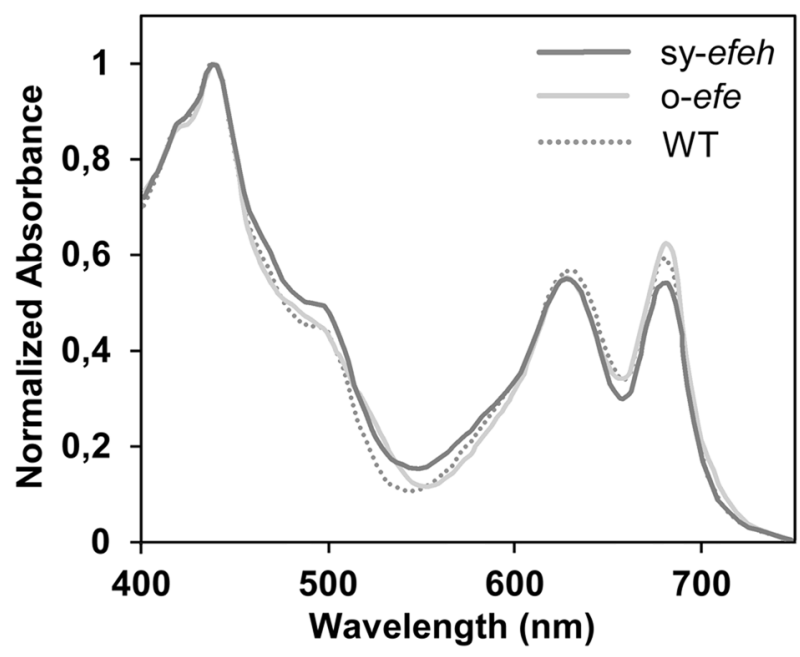

Fig. 4 Absorption spectra of Synechococcus elongatus PCC 7942 wild type (dotted line), Synechococcus:o-efe (solid light grey line) and Synechococcus:sy-efeh (solid dark grey line). Absorption curves were obtained from three replicates of each strain and normalized to $\mathrm{OD}_{750}$

effects on Synechococcus even at saturating concentrations (Fig. 5).

\section{The engineered strains maintain the capacity to produce ethylene in long-term cultivation}

In order to further evaluate the stability of the Synechococcus ethylene-producing strains in long-term incubation, the cultures were subjected to a 16-week step-wise batch cultivation, in which the cultures were diluted once a week in fresh BG11 medium and analysed for productivity at given time-points 


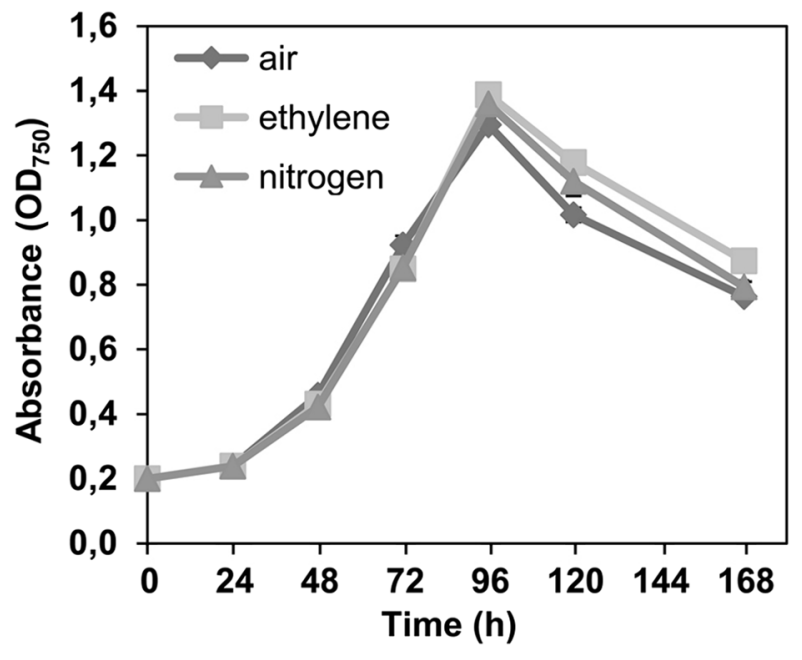

Fig. 5 Evaluation of the tolerance of Synechococcus elongatus PCC 7942 wild type towards supplemented ethylene. The cell cultures $(20 \mathrm{~mL})$ with $50 \mathrm{mM}$ of bicarbonate were incubated for 7 days in sealed $160 \mathrm{~mL}$ serum bottles under ethylene atmosphere (squares). As controls, parallel cultures were incubated with air (diamonds) and with pure nitrogen (triangles). $(n=3$; error bars represent SD). The decline in growth after $96 \mathrm{~h}$ is primarily due to the depletion of bicarbonate from the air-tight cultivation flasks. Statistically significant differences were not observed in cell growth between the alternative culture conditions ( $t$ test, $p \leq 0.05$ )

(Fig. 6). The results clearly demonstrated that, despite some batch-specific fluctuation, the overall capacity to produce ethylene was not lost nor significantly reduced in over 3-month expression trials.

\section{Supplementation of efe substrates does not significantly improve productivity}

To obtain more information on the key factors limiting ethylene productivity of the engineered Synechococcus strains, the production cultures were incubated in the presence of the two primary substrates of efe, 2-oxoglutarate and L-arginine. Although the uptake of the compounds from the medium was expected to be at least partially limited for Synechococcus (Vázquez-Bermúdez et al. 2000; Montesinos et al. 1997) a clear increase in ethylene formation was observed for both strains supplemented with the two substrates (Fig. 7). However, this improvement was rather subtle, with average values remaining under $40 \%$ at best, and apparently susceptible to relatively minor alterations, as observed in the different response of the strains towards 2-oxoglutarate and L-Arginine when supplied one at a time.

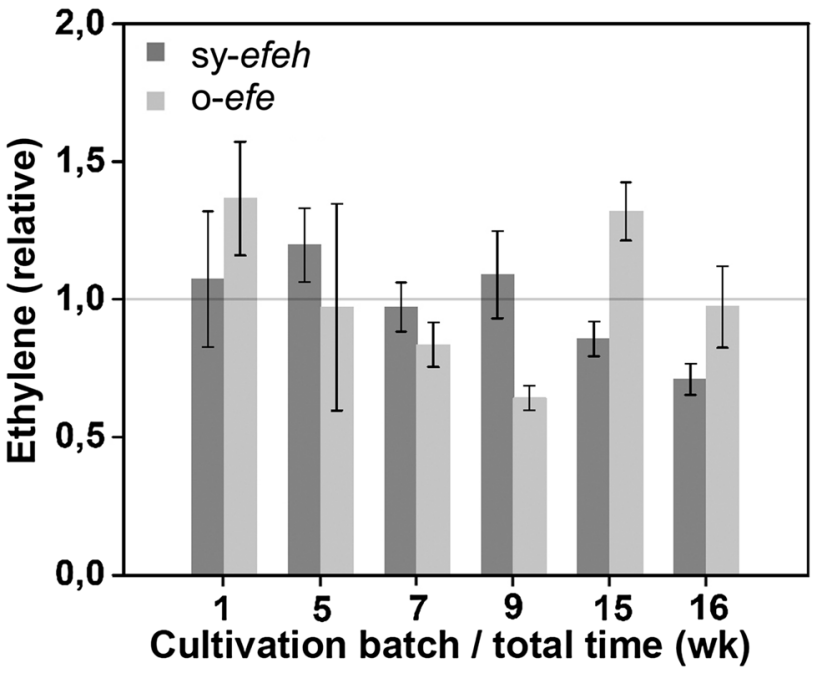

Fig. 6 Relative long-term ethylene productivity recorded for Synechococcus elongatus PCC 7942 sy-efeh and o-efe over-expression strains in successive batch cultures over a period of 16 weeks. The mean and standard deviations represent four biological replicates, and the data is normalized to the total calculated average (grey horizontal line). The relatively large fluctuation between the successive measurement time points ( $c f$. Data in Figs. 2,7) is due to a different experimental set-up with smaller cultures and extended incubation time between dilution and the measurement (7 days), in which minor variations in cultivation conditions have a proportionally significant effect on the recorded numerical values

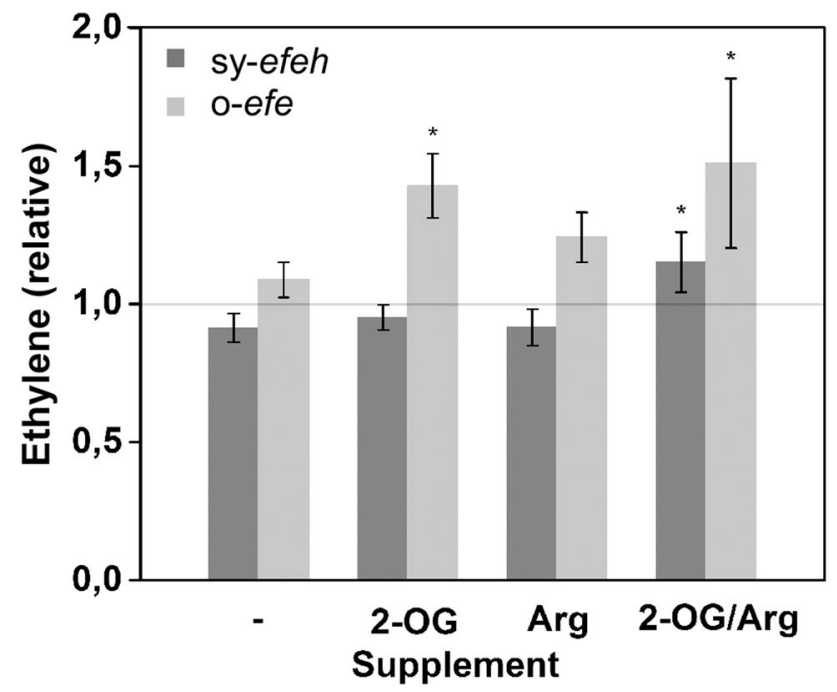

Fig. 7 Evaluation of the effect of supplemented substrates, 2-oxoglutarate $(1 \mathrm{mM})$ or/and L-arginine $(5 \mathrm{mM})$ on relative ethylene productivity in Synechococcus elongatus PCC 7942 sy-efeh and o-efe overexpression strains. The data is normalized to the calculated average of the non-supplemented strains (grey horizontal line). The mean and standard deviations represent four biological replicates. The asterisk indicates statistically significant change $(t$ test, $p \leq 0.05)$ in reference to the corresponding control without supplemented substrates 


\section{Discussion}

Ethylene is a prominent target for the development of novel biotechnological applications due to the large global market, and need for sustainable alternatives for the current petroleum-based technologies. This study focused on engineered photoautotrophic cyanobacterial systems that allow the production of ethylene directly from $\mathrm{CO}_{2}$, with a specific focus of critical strain-specific constraints associated with using Synechococcus as the host. Majority of earlier studies have focused on another cyanobacterial species Synechocystis, which has generally exhibited higher ethylene production levels and stability (Supplementary Table S1). In comparison, apart from systems with very low productivities that have been apparently stable, efe over-expression in Synechococcus has repeatedly been associated with metabolic stress and compromised expression system stability observed as decreased efficiency and eventual loss of ethylene production (Sakai et al. 1997; Takahama et al. 2003) (Supplementary Table S1). With the objective of evaluating the potential for further development, this study compared the activity of two alternative forms of the efe gene in Synechococcus, and addressed (i) the effect of the site of chromosomal integration and (ii) the impact of ethylene levels on the stability and performance of the production system.

Two different variants of efe (native gene from P. Syringae and a codon optimized sequence) were inserted at the NSI locus (Ditty et al. 2005) in Synechococcus chromosome under the regulation of $\operatorname{trc}$ promoter (Huang et al. 2010; Guerrero et al. 2012). Both expression systems were functional, producing in average around $100 \mu \mathrm{L} \mathrm{L}^{-1} \mathrm{~h}^{-1}$ $\mathrm{OD}_{750}{ }^{-1}$ ethylene (Fig. 2), without apparent loss of the capacity in extended cultivations (Fig. 6). Notably, the maximum production levels (approaching $140 \mu \mathrm{L} \mathrm{L}^{-1} \mathrm{~h}^{-1}$ $\mathrm{OD}_{750}{ }^{-1}$ ) were almost three-fold higher than earlier reported for any stable ethylene production system in Synechococcus (Sakai et al. 1997) (Supplementary Table S1), providing a starting point for comparing and evaluating the possible factors behind the problems encountered earlier. It must be emphasized that while the numbers are still somewhat lower than recorded for corresponding Synechocystis strains, and significantly below the highest reported values in the most extensively engineered systems (Mo et al. 2017), the baseline for ethylene production appears to be rather similar for the two strains.

The only form of efe that has previously been expressed in Synechococcus is the native gene form P. Syringae, which has been reported to accumulate insertion mutations resulting in efe inactivation and loss productivity in several generations (Takahama et al. 2003). Our observation that both expressed forms of efe remained equally functional in Synechococcus (Figs. 2, 3, 4) confirmed the expectation that the nucleotide sequence per se does not play any critical role in determining system integrity. Comparison of the different expression strategies used in Synechococcus (Supplementary Table S1), however, reveals that the unstable systems specifically apply $p s b A I$ locus for expression cassette integration (Takahama et al. 2003), or contain sequence elements (promoter and terminator sequences) which may promote homologous recombination at this site (Sakai et al. 1997). It is conceivable that these approaches render the endogenous Synechococcus $p s b A I$ gene inactive and defective in the production of the specific photosystem II reaction center protein D1, which is essential under normal growth conditions (Golden et al. 1986; Aro et al. 1993). It is important to note here that the expression of alternative $p s b A$ genes in response to environmental cues, as well as the function of the corresponding D1 proteins, are critically different in Synechococcus and Synechocystis (Mulo et al. 2009). This explains why psbAI in Synechocystis, unlike in Synechococcus, can be disrupted without compromising viability (Varman et al. 2013; Yu et al. 2013), and emphasizes the crucial importance of taking host-specific features into account when selecting the expression strategy for a particular organism.

In regards to acute toxicity, the study confirms that ethylene in itself does not induce any detectable adverse effects on the growth or viability of Synechococcus even when supplied at saturating concentrations in prolonged incubation (Fig. 5). Thus, interference of ethylene in native metabolic functions would not pose limitations for using Synechococcus as a host for biotechnological applications. One of the bottlenecks which have been proposed for ethylene biosynthesis, however, is the depletion of 2-oxoglutaratederived building blocks in the cell (Takahama et al. 2003) that would compromise a wide range of native metabolic activities including biosynthesis of proteins and nucleic acids. Despite production levels which were comparable with earlier reports (Sakai et al. 1997), such adverse effects were not observed in the current study, and the host cells appeared not to suffer from biosynthetic burden resulting from the shortage of 2-oxoglutarate. In addition, even though the uptake of extracellular substrates is likely to be at least partly restricted by the diffusion through the membrane, the relatively moderate effect observed for 2-oxoglutarate and L-arginine supplementation on ethylene production (Fig. 7) reinforces the view that also other factors besides substrate limitation currently constraint the system.

Our conclusion is that the key limiting factors in using Synechococcus as a host for photoautotrophic production of ethylene are not related to adverse effects caused efe overexpression or the presence of ethylene. Instead, the biosynthetic bottlenecks may be similar to those identified for Synechocystis: (i) Restricted overall flux towards the TCA 
cycle, and (ii) strictly regulated feedback inhibition of the three first catalytic steps of the cycle including conversion of isocitrate to 2-oxoglutarate, which could be reinforced by (iii) enhancing the expression of efe to increase the efficiency of ethylene formation, thus increasing the biosynthetic pull throughout the pathway.

Acknowledgements Open access funding provided by University of Turku (UTU) including Turku University Central Hospital. This study was funded by European Union Seventh Framework Programme (Grant \#256808), Academy of Finland CoE (Grant \#307335), Finnish Cultural Foundation (Grant \#85141444), Tekes (Grant \#40128/14), and NordForsk NCoE (Grant \#82845).

\section{Compliance with ethical standards}

Conflict of interest The authors declare that they have no conflict of interest.

Ethical approval This article does not contain any studies with human participants or animals performed by any of the authors.

Open Access This article is distributed under the terms of the Creative Commons Attribution 4.0 International License (http://creativeco mmons.org/licenses/by/4.0/), which permits unrestricted use, distribution, and reproduction in any medium, provided you give appropriate credit to the original author(s) and the source, provide a link to the Creative Commons license, and indicate if changes were made.

\section{References}

Aro EM, Virgin I, Andersson B (1993) Photoinhibition of photosystem. II. Inactivation, protein damage and turnover. Biochim Biophys Acta 1143(2):113-134

Berla BM, Saha R, Immethun CM, Maranas CD, Moon TS, Pakrasi HB (2013) Synthetic biology of cyanobacteria: unique challenges and opportunities. Front Microbiol 4:246

Carbonell V, Vuorio E, Aro E-M, Kallio P (2016) Sequence optimization of efe gene from $P$. syringae is not required for stable ethylene production in recombinant Synechocystis sp. PCC 6803. IJIRTS 4:30-35

Ditty JL, Canales SR, Anderson BE, Williams SB, Golden SS (2005) Stability of the Synechococcus elongatus PCC 7942 circadian clock under directed anti-phase expression of the kai genes. Microbiology 151:2605-2613

Dong JG, Fernández-Maculet JC, Yang SF (1992) Purification and characterization of 1-aminocyclopropane-1-carboxylate oxidase from apple fruit. PNAS 89:9789-9793

Eckert C, Xu W, Xiong W, Lynch S, Ungerer J, Tao L, Gill R, Maness $\mathrm{PC}$, Yu J (2014) Ethylene-forming enzyme and bioethylene production. Biotechnol Biofuels 7:33

Fukuda H, Fujii T, Ogawa T (1986) Preparation of a cell-free ethyleneforming system from Penicillium digitatum. Agric Biol Chem 50:977-981

Fukuda H, Takahashi M, Fujii T, Tazaki M, Ogawa T (1989) An NADH:Fe(III)EDTA oxidoreductase from Cryptococcus albidus: an enzyme involved in ethylene production in vivo? FEMS Microbiol Lett 51:107-111
Fukuda H, Sakai M, Nagahama K, Fujii T, Matsuoka M, Inoue Y, Ogawa T (1994) Heterologous expression of the gene for the ethylene-forming enzyme from Pseudomonas Syringae in the cyanobacterium Synechococcus. Biotechnol Lett 16:2-7

Geerts D, Bovy A, de Vrieze G, Borrias M, Weisbeek P (1995) Inducible expression of heterologous genes targeted to a chromosomal platform in the cyanobacterium Synechococcus sp. PCC 7942. Microbiology 141(4):831-841

Golden SS, Brusslan J, Haselkorn R (1986) Expression of a family of psbA genes encoding a photosystem II polypeptide in the cyanobacterium Anacystis nidulans R2. EMBO J 5:2789-2798

Gottwald S, Samans B, Lück S, Friedt W (2012) Jasmonate and ethylene dependent defence gene expression and suppression of fungal virulence factors: two essential mechanisms of Fusarium head blight resistance in wheat? BMC Genomics 13:369

Guerrero F, Carbonell V, Cossu M, Correddu D, Jones PR (2012) Ethylene synthesis and regulated expression of recombinant protein in Synechocystis sp. PCC 6803. PLoS ONE 7:e50470

Hagemann M, Hess WR (2018) Systems and synthetic biology for the biotechnological application of cyanobacteria. Curr Opin Biotechnol 49:94-99

Huang H-H, Camsund D, Lindblad P, Heidorn T (2010) Design and characterization of molecular tools for a synthetic biology approach towards developing cyanobacterial biotechnology. Nucleic Acids Res 38:2577-2593

Kuchmina E, Klähn S, Jakob A, Bigott W, Enke H, Dühring U, Wilde A (2017) Ethylene production in Synechocystis sp. PCC 6803 promotes phototactic movement. Microbiology 163:1937-1945

Latiff ZA, Aziz AA, Supriyo B, Said M (2008) Viability study of ethylene $\left(\mathrm{C}_{2} \mathrm{H}_{4}\right)$ as an alternative fuel for gasoline engine. Jurnal Mekanikal 26(2):151-161

Lee TC, Xiong W, Paddock T, Carrieri D, Chang IF, Chiu HF, Ungerer J, Hank Juo SH, Maness PC, Yu J (2015) Engineered xylose utilization enhances bio-products productivity in the cyanobacterium Synechocystis sp. PCC 6803. Metab Eng 30:179-189

Mackey SR, Ditty JL, Clerico EM, Golden SS (2007) Detection of rhythmic bioluminescence from luciferase reporters in cyanobacteria. Methods Mol Biol 362:115-129

Matsuoka M, Kazutaka T, Takahira O (2001) Gene replacement in cyanobacteria mediated by a dominant streptomycin-sensitive rps12 gene that allows selection of mutants free from drug resistance markers. Microbiology 147:2077-2087

Mo H, Xie X, Zhu T, Lu X (2017) Effects of global transcription factor NtcA on photosynthetic production of ethylene in recombinant Synechocystis sp. PCC 6803. Biotechnol Biofuels 10:145

Montesinos ML, Herrero A, Flores E (1997) Amino acid transport in taxonomically diverse cyanobacteria and identification of two genes encoding elements of a neutral amino acid permease putatively involved in recapture of leaked hydrophobic amino acids. J Bacteriol 179:853-862

Mulo P, Sicora C, Aro EM (2009) Cyanobacterial psbA gene family: optimization of oxygenic photosynthesis. Cell Mol Life Sci 66:3697-3710

Nagahama K, Ogawa T, Fujii T, Tazaki M, Tanase S, Morino Y, Fukuda H (1991) Purification and properties of an ethyleneforming enzyme from Pseudomonas syringae pv. phaseolicola PK2. Microbiology 137(10):2281-2286

Ogawa T, Takahashi M, Fujii T, Tazaki M, Fukuda H (1990) The role of NADH:Fe(III)EDTA oxidoreductase in ethylene formation from 2-keto-4-methylthiobutyrate. J Ferment Bioeng 69:287-291

Oliver NJ, Rabinovitch-Deere CA, Carroll AL, Nozzi NE, Case AE, Atsumi S (2016) Cyanobacterial metabolic engineering for biofuel and chemical production. Curr Opin Chem Biol 35:43-50

Petrochemical (2015) The ethylene technology report. In: Research and markets, p 200 
Sakai M, Takahira O, Masayoshi M, Hideo F (1997) Photosynthetic conversion of carbon dioxide to ethylene by the recombinant cyanobacterium, Synechococcus sp. PCC 7942, which harbors a gene for the ethylene-forming enzyme of Pseudomonas syringae. J Ferment Bioeng 84:434-443

Sun T, Li S, Song X, Diao J, Chen L, Zhang W (2018) Toolboxes for cyanobacteria: recent advances and future direction. Biotechnol Adv 36:1293-1307

Takahama K, Masayoshi M, Kazuhiro N, Takahira O (2003) Construction and analysis of a recombinant cyanobacterium expressing a chromosomally inserted gene for an ethylene-forming enzyme at the psbAI locus. J Biosci Bioeng 95:302-305

Ungerer J, Ling T, Mark D, Maria G, Pin-Ching M, Jianping Y (2012) Sustained photosynthetic conversion of $\mathrm{CO}_{2}$ to ethylene in recombinant cyanobacterium Synechocystis 6803. Energy Environ Sci 5:8998-9006

Varman AM, Xiao Y, Pakrasi HB, Tang YJ (2013) Metabolic engineering of Synechocystis sp. strain PCC 6803 for isobutanol production. Appl Environ Microbiol 79:908-914

Vázquez-Bermúdez MF, Herrero A, Flores E (2000) Uptake of 2-oxoglutarate in Synechococcus strains transformed with the Escherichia coli kgtP gene. J Bacteriol 182:211-215

Veetil VP, Angermayr SA, Hellingwerf KJ (2017) Ethylene production with engineered Synechocystis sp PCC 6803 strains. Microb Cell Fact 16:34

Wang J, Araki T, Ogawa T, Matsuoka M, Fukuda H (1999) A method of graphically analyzing substrate-inhibition kinetics. Biotechnol Bioeng 62:402-411

Wang J-S, Araki T, Matsuoka M, Ogawa T (2000) A Model of photoinhibition related to mRNA instability in ethylene production by a recombinant cyanobacterium. J Theor Biol 202:205-211
Weingart H, Ullrich H, Geider K, Völksch B (2001) The role of ethylene production in virulence of Pseudomonas syringae pvs. glycinea and phaseolicola. Phytopathology 91:511-518

Xiong W, Morgan JA, Ungerer J, Wang B, Maness P-C, Yu J (2015) The plasticity of cyanobacterial metabolism supports direct $\mathrm{CO}_{2}$ conversion to ethylene. Nat Plants 1:15053

Yanisch-Perron C, Vieira J, Messing J (1985) Improved M13 phage cloning vectors and host strains: nucleotide sequences of the M13mp18 and pUC19 vectors. Gene 33:103-119

Yu Y, You L, Liu D, Hollinshead W, Tang YJ, Zhang F (2013) Development of Synechocystis sp. PCC 6803 as a phototrophic cell factory. Mar Drugs 11(8): 2894-2916

Zavřel T, Knoop H, Steuer R, Jones PR, Červený J, Trtílek M (2016) A quantitative evaluation of ethylene production in the recombinant cyanobacterium Synechocystis sp. PCC 6803 harboring the ethylene-forming enzyme by membrane inlet mass spectrometry. Bioresour Technol 202:142-151

Zhou J, Zhu T, Cai Z, Li Y (2016) From cyanochemicals to cyanofactories: a review and perspective. Microb Cell Fact 15:2

Zhu T, Xiaoman X, Zhimin L, Xiaoming T, Xuefeng L (2015) Enhancing photosynthetic production of ethylene in genetically engineered Synechocystis sp. PCC 6803. Green Chem 17:421-434

Publisher's Note Springer Nature remains neutral with regard tojurisdictional claims in published maps and institutional affiliations. 